\title{
Experimental infection parameters in Galea spixii (Rodentia: Caviidae) with Leishmania infantum chagasi
}

\author{
Patrícia Batista Barra Medeiros Barbosa, Paula Viviane Sousa de Queiroz, \\ Selma Maria B Jerônimo', Maria de Fátima Freire de Melo Ximenes/2/+ \\ Faculdade de Ciências da Saúde, Universidade Estadual do Rio Grande do Norte, Natal, RN, Brasil 'Departamento de Microbiologia e \\ Parasitologia ${ }^{2}$ Departamento de Bioquímica, Universidade Federal do Rio Grande do Norte, Natal, RN, Brasil
}

In order to better understand the epidemiological transmission network of leishmaniasis, an endemic disease in Northeast Brazil, we investigated the susceptibility of Spix yellow-toothed cavies (Galea spixii) to the Leishmania infantum chagasi parasite. Nine cavies were experimentally infected, separated into three groups and monitored at 30, 90 and 180 days, respectively. Amastigotes were identified in the spleen slides of two cavies killed 180 days after infection. Antibodies against the L. i. chagasi were identified in one of the cavies. This demonstrates that $\mathrm{G}$. spixii is in fact capable of maintaining a stable infection by L. i. chagasi without alterations in biochemical and hematological parameters of the host and without perceivable micro and macroscopic lesions.

Key words: Galea spixii - Leishmania infantum chagasi - animal hosts

American visceral leishmaniasis (AVL) remains an important public health problem in Brazil. The existence of wild reservoirs, many still unknown, has compromised the control measures for this zoonosis, which currently consist of only the elimination of parasite-positive dogs, the main urban reservoirs of Leishmania infantum chagasi (Lainson et al. 2002).

Several species of rodents are suspected to be the principle wild reservoirs of the Leishmania species responsible for the tegumental form of the disease. Cases of natural infection by L. $i$. chagasi registered in Rattus rattus (Zuleta et al. 1999, Oliveira et al. 2005), in Trychomys apereoides (Oliveira et al. 2005) and Proechimys canicollis (Travi et al. 1998) illustrate the need for a better understanding of the role of these animal reservoirs in AVL transmission.

Spix yellow-toothed cavies (Galea spixii Wagler) are small rodents belonging to the suborder Hystricognathi, family Caviidae, subfamily Caviinae. They are tailless and have a dark gray dorsal surface and white ventral surface with infraocular and postauricular white spots. These rodents are morphologically similar to the other Caviinae species; however, their differentiating characteristic is their yellow incisors (Lacher 1981). They are found in all the states of Northeast Brazil. Although studies have been carried out to address raising these animals in captivity (Pinheiro et al. 1989), little research has been done on the zoonoses that they might transmit.

The purpose of this study was to investigate the susceptibility of Spix yellow-toothed cavies to the L. i. cha-

Financial support: CNPq, CAPES

+Corresponding author: ximenes@cb.ufrn.br

Received 24 March 2008

Accepted 11 September 2008 gasi parasite through the experimental infection of these animals in order to better understand visceral leishmaniasis epidemiological chains in Northeast Brazil.

\section{MATERIALS AND METHODS}

The experimental protocol was approved by the Research Ethical Committee of the Universidade Federal do Rio Grande do Norte. Permission to capture 21 Spix yellow-toothed cavies (Figure) was given by the Instituto Brasileiro do Meio Ambiente e dos Recursos Naturais Renováveis.

The animals were captured in peripheral areas of Mossoró, a city located in the western part of the state of Rio Grande do Norte, Northeast Brazil. After clinical examination, the cavies were sorted randomly and housed in metal cages $(80 \times 45 \times 60 \mathrm{~cm})$ which hold a maximum of four animals each. The cages contained feeders, water dispensers and shelters and were kept isolated in a controlled room. Food was provided ad libitum and replaced daily. It consisted of rodent ration (Labina, Purina) complemented with sweet potato, leafy greens [lettuce, carrot leaves and chopped elephant grass (Pennisetum purpureum)] and green beans.

After a 40-day period of observation and adaptation to the experimental conditions, 13 cavies were allocated to four groups, with G1 (4 animals) as the control. The animals of the remaining groups (G2, G3 and G4) were intraperitonially inoculated with $10^{7}$ promastigotes of $L$. $i$. chagasi obtained from the spleen and liver of naturally infected dogs and monitored for 30, 90 and 180 days, respectively. To control parasite virulence, two hamsters were infected under the same conditions as the cavies. All animals in all groups were clinically assessed once a week. The parameters adopted included the following: skin elasticity, the color of the buccal and conjunctive mucosas, abdominal sensitivity and body coat. Rectal temperature and total weight gain were also measured. 


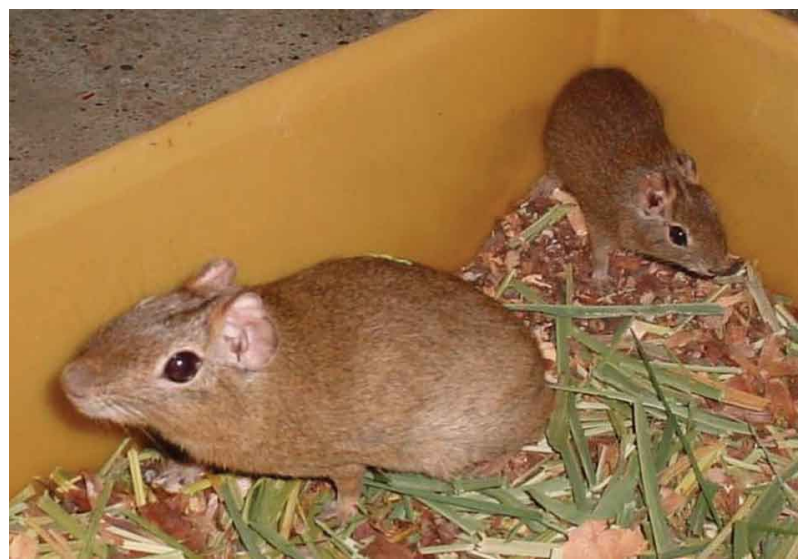

Galea spixii (Rodentia: caviidae).

After the post-infection period, the animals were anesthetized with an intramuscular injection of $75 \mathrm{mg} /$ $\mathrm{Kg}$ of tiletamine chloride and zolazepam chloride (Zoletil 50). Blood collected by cardiac punction was used to perform a complete hemogram with an automatic cell counter (Cell-dyn 1400) and a differential leukocyte count in blood smears stained by the Panotico method (methylene blue, eosin, ethyl alcohol, Laborclin) and to obtain serum to determine total protein and albumin values using commercial tests (Labtest) and anti-Leishmania antibody studies.

Peripheral blood aliquots, as well as fragments of the liver, spleen, popliteal and mesenteric lymph nodes, were used to prepare Giemsa-stained slides and biphasic culture medium (NNN/Schneider). The cultures were incubated at $24^{\circ} \mathrm{C}$ for four weeks and observed daily. Formaldehyde spleen fragments were used to prepare histological slides stained with Giemsa and hematoxylin-eosin.

Given the small spleen size, after preparation of slides, culture and histopathological examination, there was no material left for DNA extraction and subsequent parasitical study. For this reason, the procedure (DNA extraction) was performed only on the liver. A $100 \mathrm{mg}$ fragment of liver homogenized in $1.2 \mathrm{~mL}$ of TE solution (10 mM Tris-CI, $\mathrm{pH} 8.0 ; 0.1 \mathrm{mM}$ EDTA, $\mathrm{pH}$ 8.0) was digested at $55^{\circ} \mathrm{C}$ for $2 \mathrm{~h}$ in $40 \mu \mathrm{L}$ of $20 \%$ SDS and $60 \mu \mathrm{L}$ of proteinase $\mathrm{K}(20 \mathrm{mg} / \mathrm{mL})$. After successive extractions with phenol, isoamylic phenol/chloroform/alcohol (25:24:1) and isoamylic chloroform/alcohol (24:1) and precipitation with two volumes of ethanol, the DNA was resuspended in $200 \mu \mathrm{L}$ of TE and incubated at $37^{\circ} \mathrm{C}$ for 30 min before being frozen at $-20^{\circ} \mathrm{C}$.

The polymerase chain reaction (PCR) was carried out using complementary oligonucleotides of kinetoplast minicircle sequences from Leishmania as described by Smyth et al. (1992). To the reaction we added $20 \mathrm{ng}$ of DNA extracted at a mixture of $4.185 \mu \mathrm{L}$ of bidistilled sterile water, $1.25 \mu \mathrm{L}$ of PCR buffer (100 mM Tris-HCI, $500 \mathrm{mM} \mathrm{KCI}, 15 \mathrm{mM} \mathrm{MgCl}, \mathrm{pH} \mathrm{8.3),} 1.25 \mu \mathrm{L}$ of each oligonucleotide, at a concentration of $20 \mathrm{nmol}$ (right -5 ' GGG GTT GTA AAA TAG and reverse -5' CCA GTT TCC CGC CCC G), $2.5 \mu \mathrm{L}$ of a solution containing 1.25
$\mathrm{mM}$ desoxyribonucleoside triphosphate and $0.0625 \mu \mathrm{L}$ of $5 \mathrm{U} / \mu \mathrm{L}$ of thermo-resistant DNA polymerase. The samples were initially denatured at $93^{\circ} \mathrm{C}$ for $30 \mathrm{~s}$. Annealing occurred at $60^{\circ} \mathrm{C}$ for $1 \mathrm{~min}$, and the final extension at $72^{\circ} \mathrm{C}$ for $1 \mathrm{~min}$. Identification of the PCR product was performed by agarose gel electrophoresis

The study of anti-Leishmania antibodies in the infected animals was performed by means of immunoenzyme trial, using the recombinant $\mathrm{rK} 39$ protein of $L$. $i$. chagasi (Qu et al. 1994) and the total extract of L. i. chagasi (raw extract). Peroxidase-stained protein-A (protein $\mathrm{HRP}$ conjugate grade/CN biomed OH44202) was diluted in $0.1 \%$ PBS-Tween 20 at 1:10000 (for the rK39 antigen) and $1: 1000$ (for the raw extract).

Serum from AVL-positive dogs was used as control and to obtain cutoff points ( 0.159 for rK39 and 0.050 for the raw extract); we used serum from the control group animals (G1) and from four cavies born in the laboratory during the study.

To compare the means of the parameters analyzed, we used the Kruskal-Wallis non-parametric test and Statistica software, version 6.0, at a significance level of $5 \%$.

\section{RESULTS}

At the moment of capture, no clinical sign suggestive of leishmaniasis or of any other infirmity was observed in the cavies. During the 40-day observation period, seven animals died and necropsy observations showed no lesions compatible with leishmaniasis. Another cavy was eliminated from the experiment for having undergone antibiotic treatment for wounds received in a fight.

During monitoring after $L$. $i$. chagasi infection, a wide variation in total weight gain was observed among the animals. However, there were no significant differences between the means of the different groups. Rectal temperature also did not differ statistically between control and infected animals. Considering the controls and the infected animals, the amplitude and the temperatures of all animals ranged from $36-40^{\circ} \mathrm{C}$. The mean rectal temperatures (mean \pm standard deviation) observed in the control group animals and in those infected for 30, 90 and 180 days were $38.1^{\circ} \mathrm{C} \pm 0.7 ; 37.3^{\circ} \mathrm{C} \pm 0.5 ; 37.9^{\circ} \mathrm{C}$ \pm 0.5 and $38.3^{\circ} \mathrm{C} \pm 0.6$, respectively.

No differences were found in the biochemical and hematological parameters of the groups (Table). Sparse amastigote forms of Leishmania were visualized in apposition on the slides and in the histological examination of the spleens of two females, both belonging to the group monitored for 180 days, and anti-Leishmania antibodies were also found in one of them. However, no pathological alterations were observed in the spleen of the animal, upon either macroscopic observation or histological examination. The DNA of $L$. $i$. chagasi was not found in all of the liver samples from all of the animals submitted to PCR.

\section{DISCUSSION}

The present study investigated the susceptibility of Spix yellow-toothed cavies (G. spixii) to the L. i. chagasi parasite by means of experimental infection. These small rodents, by virtue of their good adaptation to the inhospi- 
TABLE

Mean values and significance level of biological characteristic and hematological and biochemical parameters of the cavies

\begin{tabular}{|c|c|c|c|c|c|c|c|c|c|c|c|}
\hline \multirow{3}{*}{$\begin{array}{l}\text { Parameters } \\
\text { Animals }\end{array}$} & \multirow{2}{*}{\multicolumn{3}{|c|}{$\begin{array}{c}\text { Control } \\
(\overline{\mathrm{x}} \pm \mathrm{SD})\end{array}$}} & \multicolumn{7}{|c|}{ Post-infection period (days) } & \multirow[t]{3}{*}{$\mathrm{p}$} \\
\hline & & & & \multicolumn{2}{|c|}{$30(\overline{\mathrm{x}} \pm \mathrm{SD})$} & \multicolumn{2}{|c|}{$90(\overline{\mathrm{x}} \pm \mathrm{SD})$} & \multicolumn{3}{|c|}{$180(\overline{\mathrm{x}} \pm \mathrm{SD})$} & \\
\hline & $\mathrm{P} 1$ & $\mathrm{P} 2$ & $\mathrm{P} 4$ & P5 & P6 & P8 & $\mathrm{P} 10$ & P11 & $\mathrm{P} 12$ & $\mathrm{P} 13$ & \\
\hline Sex & $\mathrm{M}$ & $\mathrm{M}$ & $\mathrm{F}$ & $\mathrm{F}$ & $\mathrm{M}$ & $\mathrm{F}$ & $\mathrm{M}$ & $\mathrm{M}$ & $\mathrm{F}$ & $\mathrm{F}$ & \\
\hline Initial weight (g) & 247 & 221 & $281 \quad 278$ & 305 & $352 \quad 238$ & 363 & $269 \quad 182$ & 304 & 190 & 324 & \\
\hline Total weight gain (g) & \multicolumn{3}{|c|}{$24.38 \pm 17.40$} & \multicolumn{2}{|c|}{$8.66 \pm 9.52$} & \multicolumn{2}{|c|}{$22.65 \pm 10.82$} & \multicolumn{3}{|c|}{$28.55 \pm 25.22$} & 0.45 \\
\hline Total proteins $(\mathrm{g} / \mathrm{dL})$ & \multicolumn{3}{|c|}{$4.5 \pm 1.1$} & \multicolumn{2}{|c|}{$3.0 \pm 1.3$} & \multicolumn{2}{|c|}{$3.2 \pm 1.5$} & \multicolumn{3}{|c|}{$3.3 \pm 1.7$} & 0.48 \\
\hline Albumin $(\mathrm{g} / \mathrm{dL})$ & \multicolumn{3}{|c|}{$2.0 \pm 0.7$} & \multicolumn{2}{|c|}{$1.9 \pm 0.6$} & \multicolumn{2}{|c|}{$2.2 \pm 0.6$} & \multicolumn{3}{|c|}{$2.1 \pm 0.8$} & 0.88 \\
\hline Globulin (g/dL) & \multicolumn{3}{|c|}{$2.5 \pm 0.6$} & \multicolumn{2}{|c|}{$1.0 \pm 0.7$} & \multicolumn{2}{|c|}{$1.0 \pm 0.9$} & \multicolumn{3}{|c|}{$1.2 \pm 1.1$} & 0.11 \\
\hline Hematocrit (\%) & \multicolumn{3}{|c|}{$39.3 \pm 1.4$} & \multicolumn{2}{|c|}{$40.5 \pm 2.2$} & \multicolumn{2}{|c|}{$40.6 \pm 1.6$} & \multicolumn{3}{|c|}{$36.8 \pm 2.8$} & 0.23 \\
\hline Erythrocytes $\left(10^{6} / \mathrm{mm}^{3}\right)$ & \multicolumn{3}{|c|}{$6.2 \pm 0.5$} & \multicolumn{2}{|c|}{$6.0 \pm 0.4$} & \multicolumn{2}{|c|}{$5.8 \pm 0.6$} & \multicolumn{3}{|c|}{$5.3 \pm 0.7$} & 0.50 \\
\hline Hemoglobin $(\mathrm{g} / \mathrm{dL})$ & \multicolumn{3}{|c|}{$12.8 \pm 1.2$} & \multicolumn{2}{|c|}{$12.4 \pm 1.3$} & & $2.5 \pm 1.2$ & & $2 \pm 1$. & & 0.50 \\
\hline VCM (fL) & & $65.2=$ & $=1.3$ & & $.7 \pm 1.2$ & & $0.7 \pm 5.7$ & & $8 \pm 5$ & & 0.30 \\
\hline $\mathrm{HCM}(\mathrm{pg})$ & & $20.8=$ & $=0.5$ & & $.5 \pm 0.9$ & & $1.8 \pm 0.4$ & & $.2 \pm 1$. & & 0.13 \\
\hline CHCM (g/dL) & & $31.8=$ & $=0.4$ & & $.3 \pm 1.7$ & & $1.0 \pm 2.1$ & & $.5 \pm 1$. & & 0.42 \\
\hline Leukocytes $\left(10^{3} / \mathrm{mm}^{3}\right)$ & & 2.4 & $=1.6$ & & $.6 \pm 1.6$ & & $3.5 \pm 2.1$ & & $6 \pm 4$ & & 0.78 \\
\hline Platelets $\left(10^{3} / \mathrm{mm}^{3}\right)$ & & $439=$ & $=27$ & & $98 \pm 45$ & & $36 \pm 237$ & & $39 \pm 13$ & & 0.19 \\
\hline Neutrophils (\%) & & $35=$ & $=10.9$ & & $33 \pm 16.0$ & & $35 \pm 9.2$ & & $36 \pm 5$ & & 0.99 \\
\hline Eosinophils (\%) & & & $=1.9$ & & $2 \pm 1.2$ & & $1 \pm 0.6$ & & $3 \pm 2$ & & 0.41 \\
\hline Lymphocytes (\%) & & $54=$ & $=12.4$ & & $59 \pm 17.8$ & & $55 \pm 10.4$ & & $51 \pm 9$ & & 0.96 \\
\hline Monocytes $(\%)$ & & $10=$ & $=2.9$ & & $6 \pm 3.8$ & & $8 \pm 1.7$ & & $9 \pm 2$ & & 0.38 \\
\hline
\end{tabular}

table conditions of the semiarid region of Northeast Brazil, are generally found near residences and on the outskirts of rural cities (Lacher 1981, Pinheiro et al. 1989).

No differences in total weight gain and rectal temperature were observed between the animals infected and the controls. Complete hematocrit values and the biochemical parameters of total proteins (albumin and globulin) did not differ between the groups either, most likely because of the absence of severe infection causing systemic damage in the parasite-inoculated animals.

It should be pointed out that this is the first report of hematological and biochemical parameters in Spix yellow-toothed cavies.

The presence of scarce parasites and the absence of significant pathological alterations indicate a subpatent infection with low parasite load. Although there is currently no concrete evidence of natural L. i. chagasi infection in cavies, cutaneous lesions attributed to leishmanias have been recorded in another cavy species (Cavia porcellus), without identification of the species of Leishmania (Ecco et al. 2000) or have been identified and attributed to Leishmania enrietti (Medina 1946, Muniz \& Medina 1948, Machado et al. 1994).

To understand the infection in only two animals in this study, even though all animals were submitted to the same experimental condition, one must consider the genetic heterogeneity of the wild population, which implies the existence of different levels of susceptibility among the individuals, a fact that has been well established in murine models (Blackwell 1996).

This difficulty in experimentally infecting cavies suggests, even without knowledge of the cytokine profile produced, that cavies are resistant to $L$. $i$. chagasi infection. However, G. spixii are abundant, highly prolific animals, living in proximity to humans and dogs and capable of maintaining a stable infection without alterations in biochemical and hematological parameters and even without perceivable macro and microscopic lesions. Thus, we suggest further studies to help clarify the role of G. spixii cavies as hosts for L. $i$. chagasi in Northeast Brazil.

\section{REFERENCES}

Blackwell JM 1996. Genetic susceptibility to leishmanial infections: studies in mice and man. Parasitol 112: 67-74.

Ecco R, Langohr IM, Barros S, Barros CSL 2000. Leishmaniose cutânea em cobaios (Cavia porcellus). Ciência Rural 30: 225-228.

Lacher Jr TE 1981. The comparative social behavior of Kerodon rupestris and Galea spixii and the evolution of behavior in the Cavidae. Bull Carnegie Museum Nat Hist 17: 1-71.

Lainson R, Ishikawa EA, Silveira FT 2002. American visceral leishmaniasis: wild animal hosts. Trans R Soc Trop Med Hyg 96: 630-631.

Machado MI, Milder RV, Pacheco RS, Braga RR, Lainson R 1994. Naturally acquired infections with Leishmania enrietti. Muniz and Medina 1948 in guinea-pigs from São Paulo, Brazil. Parasitology 109: 135-138.

Medina HSG 1946. Estudos sobre leishmaniose. I. Primeiros casos de leishmaniose espontânea observados em cobaios. Arg Biol Tecnol 1: 29-74.

Muniz J, Medina HSG 1948. Leishmaniose tegumentar do cobaio (Leishmania enrietti $\mathrm{n}$. sp). Hospital 33: 7-25.

Oliveira FS, Pirmez C, Pires MQ, Brazil RP, Pacheco RS 2005. PCRbased diagnosis for detection of Leishmania in skin and blood of rodents from an endemic area of cutaneous and visceral leishmaniasis in Brazil. Vet Parasitol 129: 219-227. 
Pinheiro MJP, Andrade SA, Cunha JN 1989. Preservação e exploração de animais silvestres nativos: preás, cutias e mocó. Caatinga 6: 28-49.

Qu JQ, Zhong L, Masoom-Yasinzai M, Abdur-Rab M, Asku HSZ, Reed SG, Chang KP, Gilman-Sachs A 1994. Serodiagnosis of Asian leishmaniasis with a recombinant antigen from the repetitive domain of a Leishmania kinesin. Trans $R$ Soc Trop Med Hyg 88: 543-545.

Smyth AJ, Ghost A, Hassan MD, Basu D, De Bruijn MHL, Mallik KK, Barker DC 1992. Rapid and sensitive detection of Leishma- nia Kinetoplast DNA from spleen and blood samples of Kala-azar patients. Parasitology 105: 183-192.

Travi BL, OsorioY, Becerra MT, Adler GH 1998. Dynamics of Leishmania infantum infection in small mammals of the undisturbed and degraded tropical dry forests of northern Colombia. Trans $R$ Soc Trop Med Hyg 92: 275-278.

Zulueta AM, Villarroel E, Rodriguez N, Feliciangeli MD, Mazzarri M, Reyes O, Rodriguez V, Centeno M, Barrios RM, Ulrich M 1999. Epidemiologic aspects of American visceral leishmaniasis in an endemic focus in Eastern Venezuela. Am J Trop Med Hyg 61: 945-950. 